\title{
The ward round
}

\section{Rachel Armstrong}

The pirate white coat sped on, followed furiously by duckling medical students.

"Breast cancer, the signs!" The sardine cluster separated.

"Speak up, boy! Bang! Bang!" Pistol finger shot the first casualty with humiliation. Silence, then peeps of protestation and chirps of fluffy facts escaped the startled gaggle. The piper followed, cried, "Chronic obstructive airways disease, name the types!" Consultant eyes flashed laser beams. "Come on, I'm waiting!" A marooned student suffocated in his burning face, patting at the fire with his damp palms.

"D-d-don't know, sir!"

"Tut! Tut!” Triggerhappy criticism melted the boy, dripping to the sheltered aft.

"You!" I was unearthed from my white linen camouflage. "What are the features of thyrotoxicosis?" Sensing a field of neurotic mines, I navigated the reply. Weight loss; increased appetite; tremor; lid lag; exophthalmos; heat intolerance; irritability; oligomenhorrhoea; my reply was concise. The posse, stunned by brilliance, was rapidly outmanoeuvred by an imminen new case.

What was my weaponry? Hours of study? An open handbook? No.

The gross sculpture of disease is fashioned through modifications in personal physiology. A particular insult will evolve an orchestrated adaptation, a "syndrome." The clinician is trained to recognise these peculiar features and recite them, latinate verbatim.

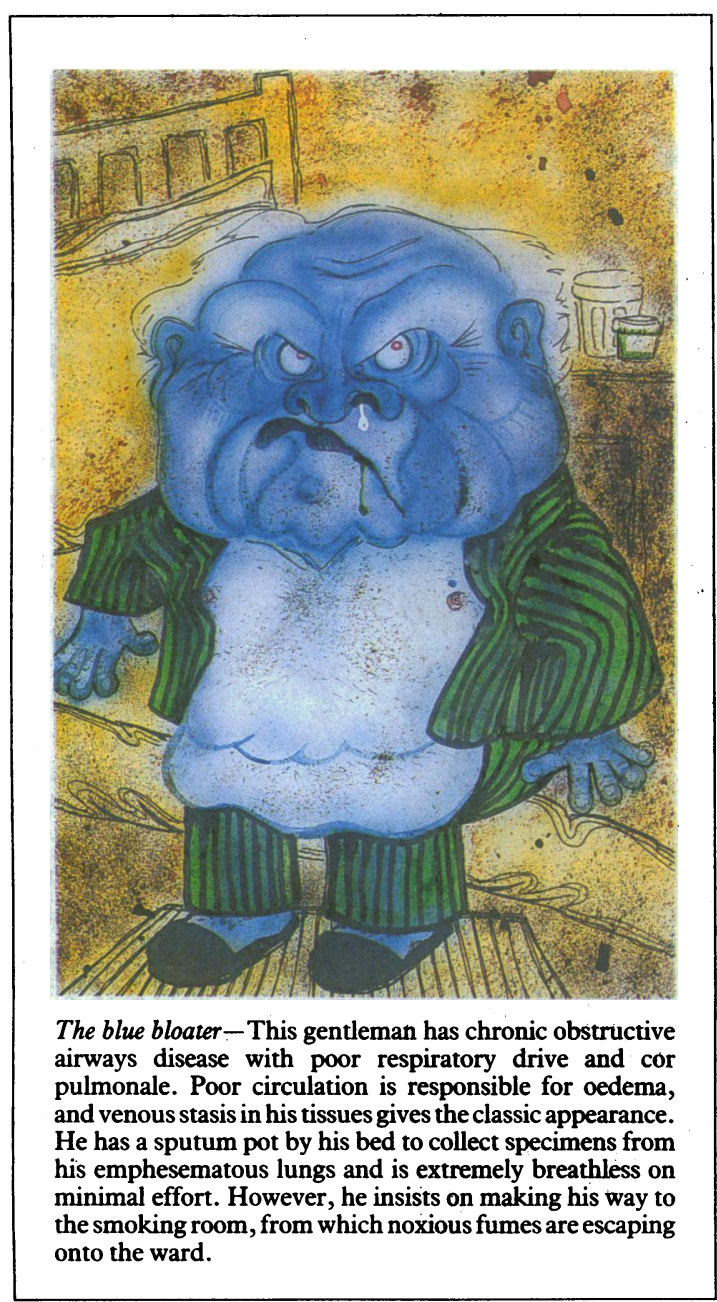

the smoking room, from which noxious fumes are escaping

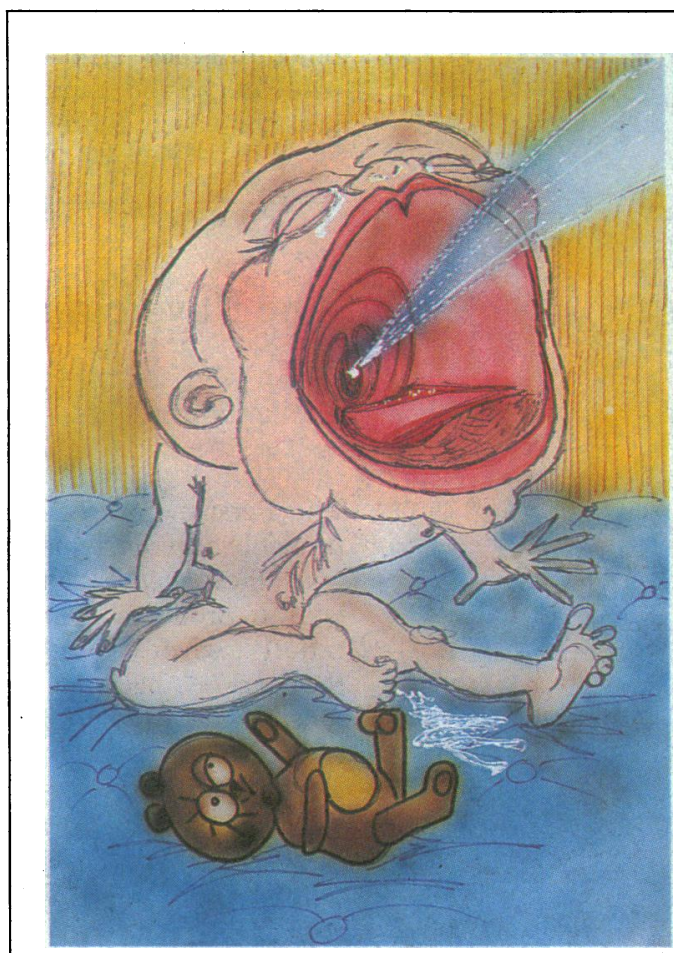

Childhood bronchitis - This child has a harsh cough and is flushed with fever. He has been swallowing his sputum, which is vomited back by the force of his expiratory effort. His tracheal "tug" and intercostal recession are accompanied by wheeze and coarse bilateral ronchi, audible without a stethoscope. Although the likely cause is of viral or bacterial origin, the one eyed teddy bear reminds us not to forget the possibility of an inhaled foreign body in this age group.

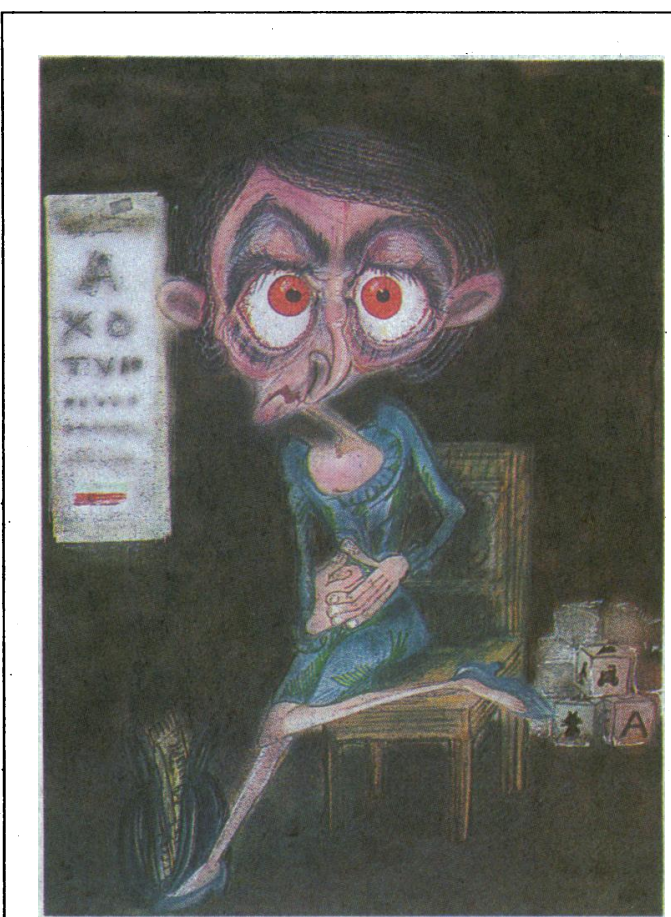

Thyrotoxicosis - This young woman has goitre, increased appetite, and diarrhoea. Her increased metabolic rate makes her extremely anxious and intolerant of heat. Unable to meet the demands of rapid metabolism and tachycardia, she has become skeletal from weight loss. She has exophthalmos from swollen tissues and lid lag as her orbits are forced forwards from their sockets. She is in danger of exposure keratitis and eventual blindness if untreated.
Rachel Armstrong, senior house officer

BMF 1992;305:1543-4 
Overformalisation of clinical terms has denuded them of everyday meaning, but they act as a valuable shorthand between doctors. The initial problem is how to master the pattern recognition and language attributed to each syndrome. Exposure to patients is mandatory, and rapid acquisition of knowledge is possible, even with an inexperienced eye. Some students learn lists but I find animation far more provocative than strings of black and white characters. My mind's camera has processed those curiosities of morbid significance and refashions the features of disease in grotesque apposition. A translation emerges through my pen which is not really a patient at all. It is caricature.

\section{The Physicians' Duel}

\section{Sheila Canby}

The Persian poet Nizami of Ganjeh (c 1140-1209)

\section{probably never imagined that stories from his magnum opus, the Khamseh ("Quintet"), would be illustrated in lavishly produced manuscripts. Yet, by the sixteenth century, when "The Physicians' Duel" was painted, the Khamseh had long since joined the repertoire of \\ illustrated works to be found in the libraries of \\ Department of Oriental Antiquities, British Museum, London Sheila Canby, assistant keeper \\ BMf 1992;305:1544 •}

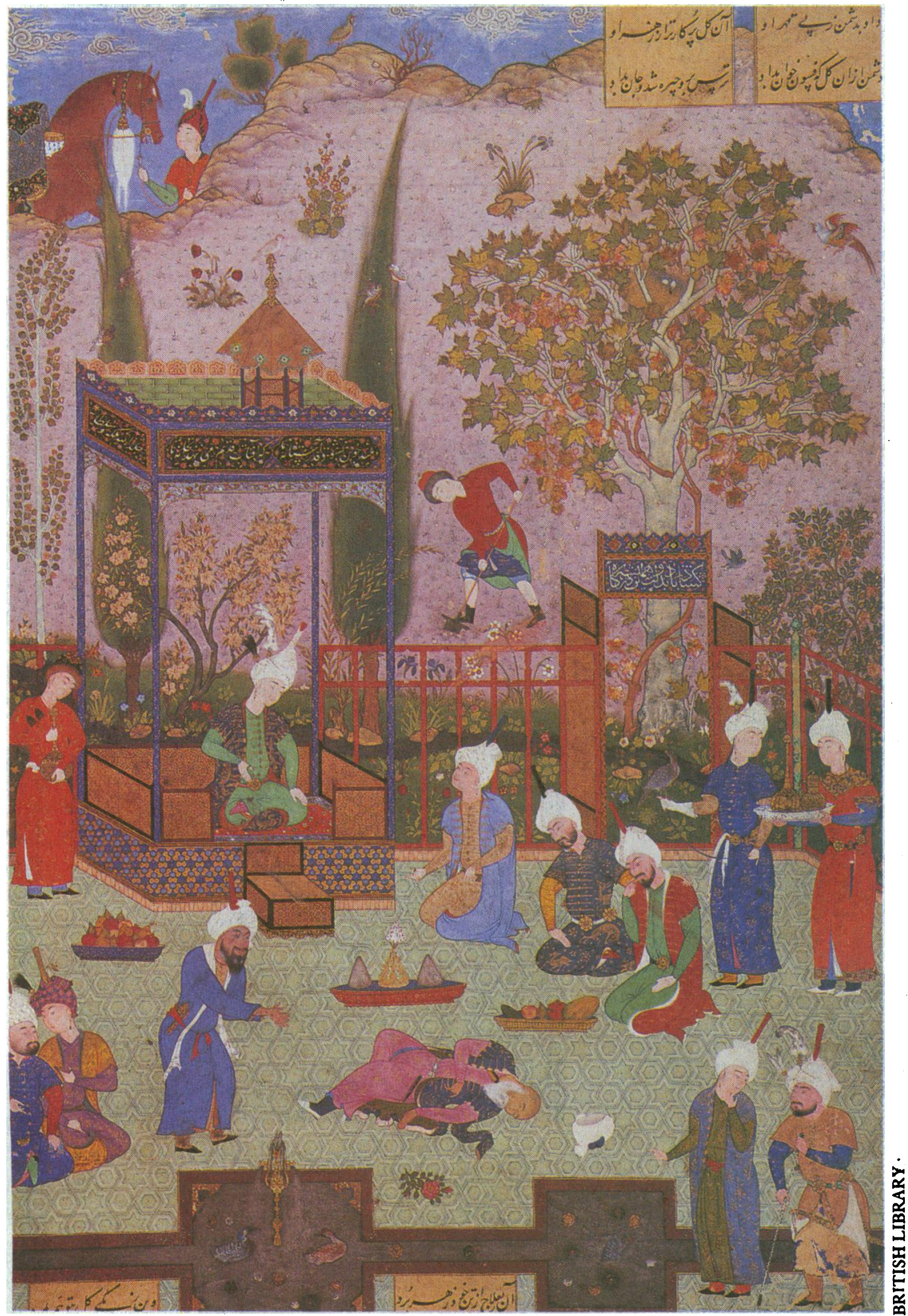

The Physicians' Duel. Khamseh of Nizami. British Library, Or 2265, fol $26 v$ established or aspiring bibliophiles. The manuscript from which "The Physicians' Duel" comes was compiled for Shah Tahmasp (reigned 1525-76) in Tabriz between 1539 and 1543. The work of five of the Shah's leading artists, its miniatures represent the pinnacle of sixteenth century Persian court painting, a glorious synthesis of the rational style of eastern Iran and the colouristic ebullience of its western half.

According to the story, two rival physicians served at the same court. To determine who was superior, the two decided on a contest of skill. The first doctor offered the other a deadly pill. Although his rival swallowed it, he immediately rendered it harmless by taking a powerful antidote. He then picked a rose and breathed a spell on it before handing it to his competitor to smell. As soon as the rival sniffed it, he collapsed dead. The power of fear proved more lethal than actual poison.

In the illustration the dead physician, with the offending rose at his side, sprawls at the feet of the victor, who hops, grins, and rubs his hands with glee. The ruler observes impassively from a pavilion at the back of the tiled terrace, while courtiers raise their fingers to their lips in astonishment. Rather than simply illustrating the narrative, the artist has included numerous details of daily life at court. At the right a falconer accompanies a servant who carries wine vessels to the king. Platters of melons, pears, apples, pomegranates, and cones of spun sugar have been placed near the assembled guests.

The story takes place within a typical Persian garden. Here the arid, mountainous background contrasts with the lush vegetation on the banks of the stream and the elegant architecture of pavilion and pools in the foreground. The stream, originally painted silver, has now tarnished to black. Beyond the stream a gardener digs the dry soil, perhaps in an attempt to extend the greensward. In the fifteenth and sixteenth centuries Persian shahs and grandees enclosed enormous tracts of land, sometimes over fifty acres, to be used as gardens. These encompassed wilderness areas, orchards and other cultivated sections, palaces, and viewing pavilions. Grids of paved watercourses punctuated by pools criss-crossed the planted sections, providing irrigation and also the pleasant sound and cooling vapours of running water. As in the painting, the pools were stocked with fish and ducks and adorned with fountains.

Both the hot climate and the nomadic life of certain sectors of Persian society resulted in many activities taking place out of doors. Until the eighteenth century, paintings of interior scenes invariably included glimpses of verdant gardens through windows or beyond walls. Although we may be grateful for advances in modern medicine and the abandonment of most magical spells in the operating theatre, we could imagine worse working environments than the elegant pavilions of the Persian garden. 